\title{
Moon Phases and Nighttime Road Crashes Involving Pedestrians
}

\author{
Michael SivaK \\ BRANDON SCHOETTLE \\ OMER TSIMHONI
}

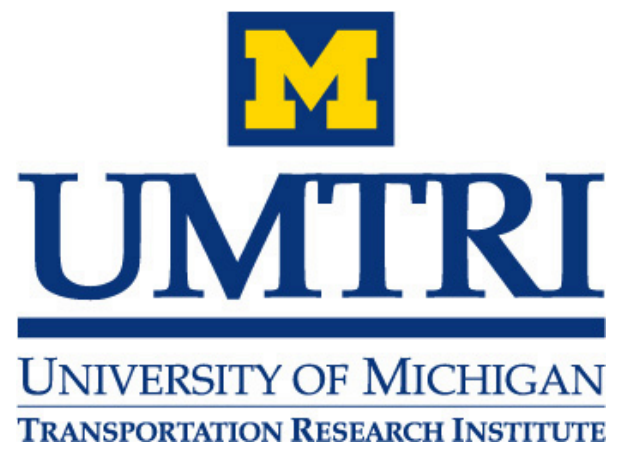


Michael Sivak Brandon Schoettle

Omer Tsimhoni

The University of Michigan

Transportation Research Institute

Ann Arbor, Michigan 48109-2150

U.S.A.

Report No. UMTRI-2007-41

September 2007 

Technical Report Documentation Page

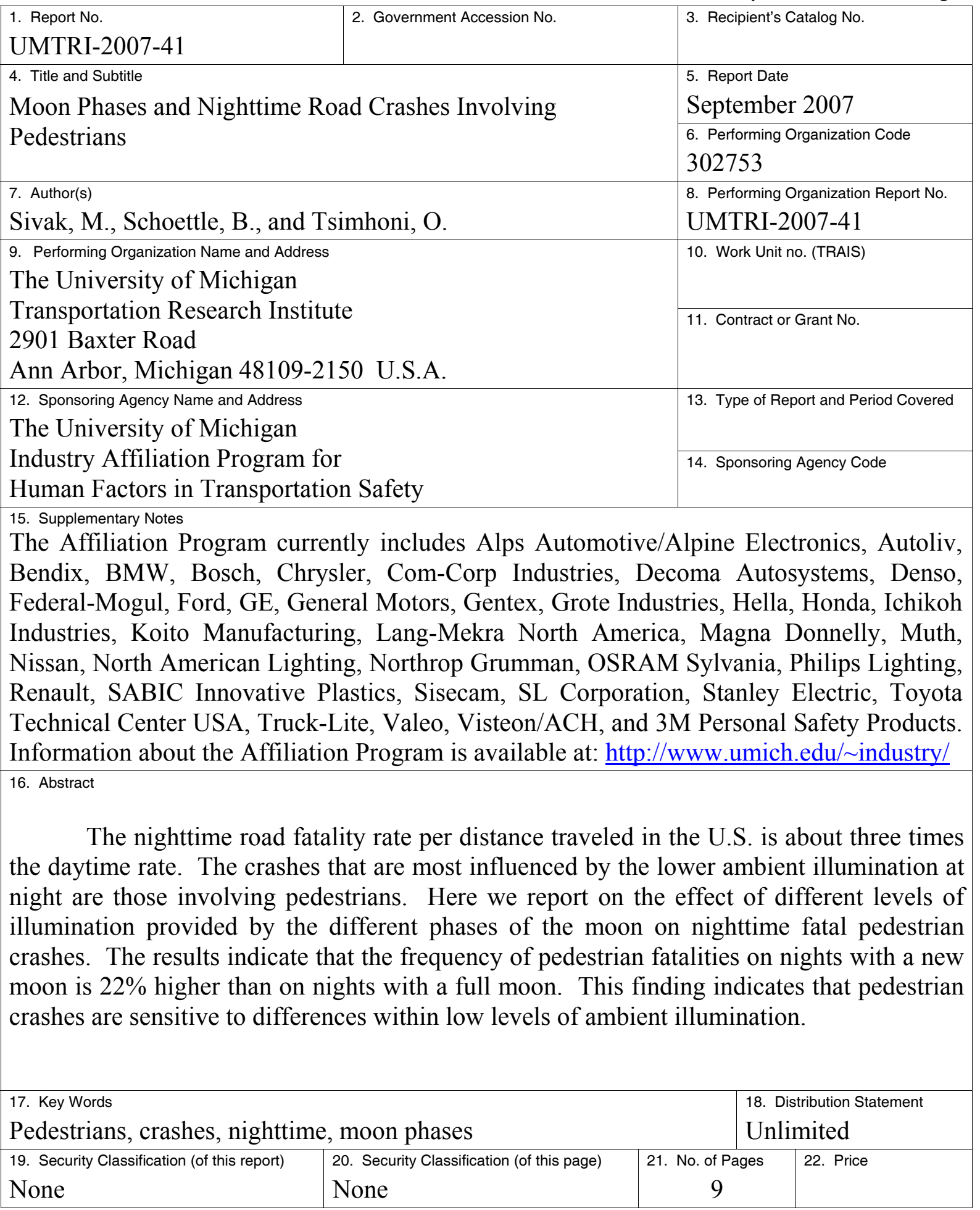




\section{Acknowledgments}

Appreciation is extended to the members of the University of Michigan Industry Affiliation Program for Human Factors in Transportation Safety for support of this research. The current members of the Program are:

\begin{tabular}{ll} 
Alps Automotive/Alpine Electronics & Lang-Mekra North America \\
Autoliv & Magna Donnelly \\
Bendix & Muth \\
BMW & Nissan \\
Bosch & North American Lighting \\
Chrysler & Northrop Grumman \\
Com-Corp Industries & OSRAM Sylvania \\
Decoma Autosystems & Philips Lighting \\
Denso & Renault \\
Federal-Mogul & SABIC Innovative Plastics \\
Ford & Sisecam \\
GE & SL Corporation \\
General Motors & Stanley Electric \\
Gentex & Toyota Technical Center, USA \\
Grote Industries & Truck-Lite \\
Hella & Valeo \\
Honda & Visteon/ACH \\
Ichikoh Industries & 3 M Personal Safety Products \\
Koito Manufacturing & \\
\hline & \\
\hline
\end{tabular}




\section{Contents}

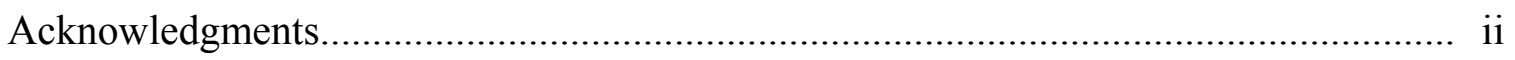

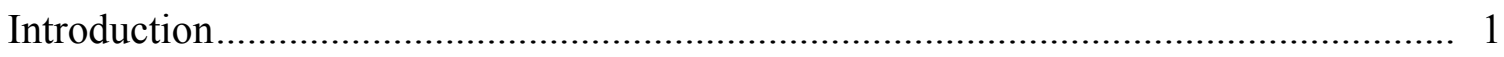

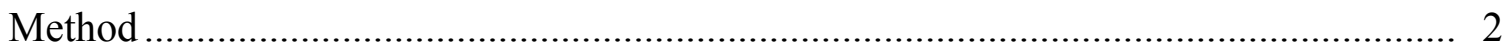

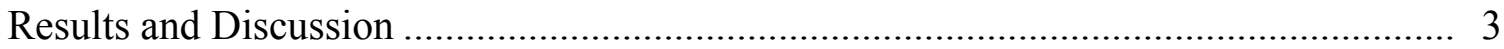

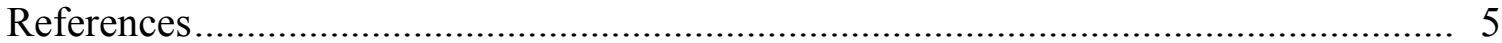




\section{Introduction}

The nighttime road fatality rate per distance traveled in the U.S. is about three times the daytime rate (NSC, 2006). Among the factors that contribute to the higher nighttime rate are the lower ambient illumination and the higher frequencies of fatigued, intoxicated, and younger drivers. The crashes that are most influenced by the lower ambient illumination at night are those involving pedestrians (Sullivan and Flannagan, 2002), most likely because of the low visibility of pedestrians.

Nighttime conditions, however, can vary in amount of ambient illumination. Here we report on the effect of different levels of illumination provided by the different phases of the moon on nighttime fatal pedestrian crashes. We examined fatal pedestrian crashes that occurred during nights with a full moon (100\% illuminated) or a new moon ( $0 \%$ illuminated). Typical ambient illuminance values on cloudless nights, measured on a horizontal surface, are 0.1 lux with a full moon and 0.001 lux with a new moon (Micron, 2007). (The corresponding values for cloudy nights are lower; among the other important factors that influence ambient illuminance are the position of the moon in the sky and atmospheric attenuation.) Thus, our analysis evaluated the influence of a major change in illumination (but all within a low range of illumination) on pedestrian crashes. 


\section{Method}

The dates on which the moon was either $100 \%$ or $0 \%$ illuminated at midnight were determined from the database of the U.S. Naval Observatory (U.S. Naval Observatory, 2007). We included all U.S. pedestrian fatalities that occurred within two time periods on the same date: between midnight and 4:59 a.m., and between 10:00 p.m. and 11:59 p.m. (local time).

We were prepared to exclude two holidays with unusual frequencies of pedestrian exposure: January 1 (a high frequency of intoxicated pedestrians), and October 31 (a high frequency of child pedestrians because of Halloween). However, the full or new moons fell only on one such day (October 31, 1997), and that day was not included in the analysis.

The census data for U.S. pedestrian fatalities were obtained from the Fatality Analysis Reporting System, maintained by the U.S. Department of Transportation (FARS, 2007). We analyzed the data for the most recent 10-year period available (from 1996 through 2005). 


\section{Results and Discussion}

The total numbers of pedestrian fatalities were 497 during full moons and 612 during new moons. Because the number of days with full and new moons were not necessarily the same in each year, the data are summarized in terms of the mean numbers of fatalities for the seven-hour time period examined and the corresponding percentage change for each year (see Table 1). A nonparametric signed test for matched pairs indicated that the frequency of pedestrian fatalities on nights with a new moon was reliably higher than on nights with a full moon, $z=2.21, p<.05$. A parametric $t$-test showed that the proportional increase in fatalities was statistically significant, $t(9)=3.85$, $p<.01$. The mean increase was $22 \%$, with the $95 \%$ confidence interval from $9 \%$ to $35 \%$.

Table 1

Mean number of pedestrian fatalities per seven-hour period during nights with full and new moons, and the corresponding percentage change.

\begin{tabular}{|c|c|c|c|}
\hline Year & Full moon & New moon & $\begin{array}{c}\text { Percentage change } \\
\text { from full to new } \\
\text { moon }\end{array}$ \\
\hline \hline 2005 & 4.2 & 5.1 & +21.4 \\
\hline 2004 & 2.6 & 4.0 & +53.8 \\
\hline 2003 & 3.9 & 4.6 & +17.9 \\
\hline 2002 & 4.3 & 4.2 & -2.3 \\
\hline 2001 & 3.0 & 3.7 & +23.3 \\
\hline 2000 & 2.9 & 3.3 & +13.8 \\
\hline 1999 & 3.4 & 3.6 & +5.9 \\
\hline 1998 & 3.7 & 4.1 & +10.8 \\
\hline 1997 & 3.3 & 4.1 & +24.2 \\
\hline 1996 & 3.5 & 5.3 & +51.4 \\
\hline Mean & 3.5 & 4.2 & $+22.0 *$ \\
\hline
\end{tabular}

* Mean of the ten yearly percentage changes. 
Pedestrian exposure on weekends is greater than on weekdays. Consequently, a control analysis was performed to examine the frequency of full moons and new moons that fell on a Friday, Saturday, or Sunday for each year that was included in this study. Out of the ten years, four had slightly higher proportions of weekend days with full moons, while six had slightly higher proportions of weekend days with new moons. The pair-wise ratios of the proportion of weekend days with a new moon to the proportion of weekend days with a full moon for each of the ten years ranged from .86 to 1.29. A correlation between these pair-wise ratios and the magnitude of the change in pedestrian fatalities from full to new moon proved not to be statistically significant $(r=-.28$, $p=.43)$.

Given the results of the preceding analysis, the differences in the ambient illumination for nights with a full moon vs. a new moon across a 10-year period are unlikely to be correlated with any other factors that are known to influence the likelihood of nighttime pedestrian crashes (e.g., alcohol intoxication of drivers or pedestrians, driver fatigue, and driver age distribution). Consequently, the present results imply that the amount of moonlight has substantial influence on pedestrian crashes. Specifically, the decrease in ambient illumination from a full moon to a new moon was associated with a $22 \%$ increase in the likelihood of pedestrian fatalities. This finding indicates that pedestrian crashes are sensitive to differences within low levels of ambient illumination. 


\section{References}

FARS [Fatality Analysis Reporting System]. (2007). FARS web-based encyclopedia. Retrieved July 8, 2007 from http://www-fars.nhtsa.dot.gov

Micron. (2007). Measuring illumination. Retrieved July 10, 2007 from http://www.micron.com/innovations/imaging/lux

NSC [National Safety Council]. (2006). Injury facts. Itasca, IL: National Safety Council.

Sullivan, J.M. and Flannagan, M.J. (2002). The role of ambient light level in fatal crashes: Inferences from daylight saving time transitions. Accident Analysis \& Prevention, 34, 487-498.

U.S. Naval Observatory. (2007). Fraction of the moon illuminated. Retrieved July 8, 2007 from http://aa.usno.navy.mil/data/docs/MoonFraction.html 